\title{
Prevalence and Risk Factors for Musculoskeletal Complaints among Dental Practitioners in Alexandria, Egypt
}

\author{
Mervat M. El Dalatony ${ }^{1}$, Eman A. Salem ${ }^{1}$, Hanan HK. Diab ${ }^{2}$ \\ ${ }^{1}$ Department of Public Health and Community Medicine, Faculty of Medicine, Menoufiya University, Egypt \\ ${ }^{2}$ Department of infection prevention and control, Faculty of Dentistry, Alexandria University, Egypt
}

\begin{abstract}
Background: Musculoskeletal complaints represent a significant occupational health issue in dentistry. In Egypt, data about the prevalence and risk factors of this problem are scarce so far. Objectives: To investigate the prevalence of musculoskeletal complaints among dental practitioners and assess the risk factors of these complaints among dentists.

Methods: Cross-sectional was used for implementation of the study. Data were collected using Nordic standard questionnaire and demographics questionnaire which were filled out by 200 dental practitioners in their offices in public dental centers in Alexandria, Egypt.

Results: A large percent of dentists (72.0\%) reported musculoskeletal symptoms in at least one site during the past 12 months. The most commonly affected sites were low back (52.0\%), upper back (44.0\%), ankles and feet $(30.0 \%)$ and knees $(29.5 \%)$. A significant difference was observed between dental specialists regarding neck pain only as it was more prevalent among periodontics $(40.9 \%)$ followed by prosthodontics (36.4\%).A significant association was found between Musculoskeletal Disorders (MSDs) and duration of work $\leq 10$ years $(\mathrm{P}=0.005)$. In addition, non-prolonged sitting was significantly associated with MSDs $(\mathrm{P}=0.026)$. Sick leaves from 1-7 days due to MSDs were reported by more than half $(54.0 \%)$ of the practitioners who complained of MSD in the last twelve months. Conclusions: A high prevalence of MSD symptoms exists among dental practitioners in Alexandria, Egypt, which affects the daily practice of nearly half of them. Lower and upper back pain symptoms were particularly common. Therefore, it is recommended that an appropriate training program be implemented to improve dentists' awareness regarding musculoskeletal symptoms and their prevention.
\end{abstract}

Available on line at:

www.ebscohost.com

$¥$ Correspondence:

Email: mervat.moh.abd@gmail.com.

Tel: +966-11-212-5555-2706

Suggested Citation: El Dalatony MM, Salem EA, Diab HH. Prevalence and Risk Factors for Musculoskeletal Complaints among Dental Practitioners in Alexandria, Egypt. Bull.HIPH.2014;44(1):25-32.

Key words Dental practitioners, Musculoskeletal disorders, Risk factors, Nordic standardized questionnaire, Egypt

\section{INTRODUCTION}

$\mathrm{M}$ usculoskeletal disorders (MSDs) are an important occupational health problem in all sectors, including healthcare industries and modern dentistry. ${ }^{(1)}$ MSDs can affect the body's muscles, joints, tendons, ligaments, and nerves from the neck to the feet. Health problems range from discomfort, minor aches, and pains, to more serious medical conditions resulting in significant social and economic consequences, such as reduced quality of dental treatment, absence from work, and even leaving the profession. ${ }^{(2,3)}$ Dentistry is visually demanding, and requires the adoption of fixed postures and the use of repetitive and precise hand and finger movements. It is considered that these biomechanical risk factors combined with psychosocial stress contribute to the development and progression of MSDs. ${ }^{(4,5)}$ Recent literature has identified MSDs as a significant occupational health issue for both dentists and dental hygienists. ${ }^{(6)}$ Also, researches done in UK, Netherlands and USA all concluded that MSDs were a major problem. ${ }^{(7)}$ Prolonged sitting in a poorly designed chair with inadequate lumbar support or adjustability has been found to be a contributing factor to muscular fatigue and low back pain. ${ }^{(8)}$ The design of dental instrumentation can play a key role in the prevention of negative health effects for its users. Although instrument design has come a long 
way since its beginning, dental professionals often select instruments based on familiarity rather than actual quality or specific properties. The goal of proper instrument selection should be to reduce force exertion while allowing for neutral joint positioning. ${ }^{(9)}$ Light positioning is a critical factor affecting the dentist's posture during clinical operation. The goal of proper lighting is to produce even, shadow-free, color-corrected illumination concentrated on the operating field. ${ }^{(10)}$ The prevalence of MSDs among dental practitioners is not well documented in Egypt that's why this study was undertaken.

The purpose of this research was to determine the prevalence of MSDs symptoms among dentists in Alexandria, Egypt and to determine their risk factors. Also, to study the effects of MSD on daily activities of the dentists.

\section{METHODS}

Study Setting \& Design: A cross sectional descriptive study was conducted over a period of 2 months (August to October 2013) to assess the prevalence of MSDs symptoms among dental practitioners in public dental centers in Alexandria city, Egypt.

Study population \& Procedure: All dental practitioners in the selected clinics were invited to participate in the study, however only $81.6 \%$ of them (200: 126 males \& 74 females) accepted. Nine dental specialties were included, i.e., GP and medicine, Oral and maxillofacial surgery, periodontics, Prosthodontics, Pedodontics and others/ Orthodontics, Endodontics \& Operative alveolar surgery.

Data collection tools: A predesigned structured demographic questionnaire and The Standardized Nordic Questionnaire (SNQ) were used for data collection. The self-administered questionnaires were handed over to the dental practitioners at their respective clinics. The method for answering the questionnaire was explained and the questionnaire was collected according to the convenience of the practitioners over a maximum period of one week. A pilot study was performed on five dental practitioners (not included in the study) before beginning the study.

BMI calculated using the following formula (WHO, 2004):

$B M I=$ weight (in kilogarm) /(hight) 2 (in square meter)

The SNQ is a reliable and valid tool that has been used repeatedly among health professionals and students in various countries, to investigate MSDs. ${ }^{(11)}$ Respondents were asked to provide information regarding social habits, qualifications and education, work habits and musculoskeletal symptoms. With the aid of a diagram, the body was divided into 11 identifiable sites, and for each site respondents were asked whether they had experienced any MSD in the previous 12 month. The questionnaires consisted of structured, forced, binary, or multiple-choice variants and were self-administered. There are two types of questionnaires: a general questionnaire, and specific ones focusing on the low back and neck/shoulders. The specific questions analyze more thoroughly the severity of the symptoms in terms of their effect on activities at work, during leisure time, and in terms of total duration of symptoms and sick leave during the preceding 12 months. ${ }^{(6)}$ Statistical Analysis: The results were collected, tabulated and statistically analyzed using SPSS statistical package, version 11. The data were presented as descriptive statistics and the (chi-square) test was done to study the association between qualitative variables. A stepwise logistic regression analysis was done to determine the adjusted odds ratio (OR) and $95 \%$ confidence interval $(\mathrm{CI})$ for the different risk factors and MSDs. $\mathrm{P}$ value $<0.05$ was considered statistically significant.

\section{Ethical considerations}

The study was approved by the institutional review board and the ethics committee of Faculty of Medicine, Menoufiya University and the Faculty of Dentistry, Alexandria University, Egypt. An informed consent to participate in the study was obtained from all practitioners after explaining the aims and concerns of the study and ensuring the Anonymity and confidentiality of their information, and their right to withdraw from the study.

\section{RESULTS}

The demographic and work details of the dental practitioners in this study are presented in table (1). The majority of the practitioners were males $(63.0 \%)$ and those aged from 31 to 40 years of age were $72.5 \%$. less than half $(44.5 \%)$ of the participants had normal weight. General dental practitioners constituted $30.0 \%$ of the participants and the remaining $70.0 \%$ were specialists. The most common specialties were oral surgery and operatives $(33.0 \%)$. The majority of the participants had less than 10 years of experience $(79.0 \%)$. Most of the practitioners $(71.5 \%)$ worked less than 40 hours / week without shift work $(87.5 \%)$ and had seen less than 20 patients per day (63.0\%). Regarding the working postures, prolonged standing posture was mentioned by $62.5 \%$ of dentists while prolonged sitting was mentioned only by $9.0 \%$ of them.

About $72.0 \%$ of the practitioners had at least one MSD symptom during the last twelve months. There were no significant association between the prevalence of MSD in the last twelve months and all demographic and work characteristics except for the duration of current work $\leq 10$ years $(84.0 \%, \mathrm{P}=0.005)$ and non- prolonged sitting during work $(88.2 \%, \mathrm{P}=0.026)$. The highest prevalence was observed in the age group from 31 to 40 years $(72.9 \%)$, males $(66.0 \%)$. MSD symptoms were non prevalent among oral surgery and operative specialists $(33.4 \%)$ followed by general practitioners $(29.9 \%)$ (Table 2$)$. 
Table 1: Demographic and work characteristics of studied dental practitioners

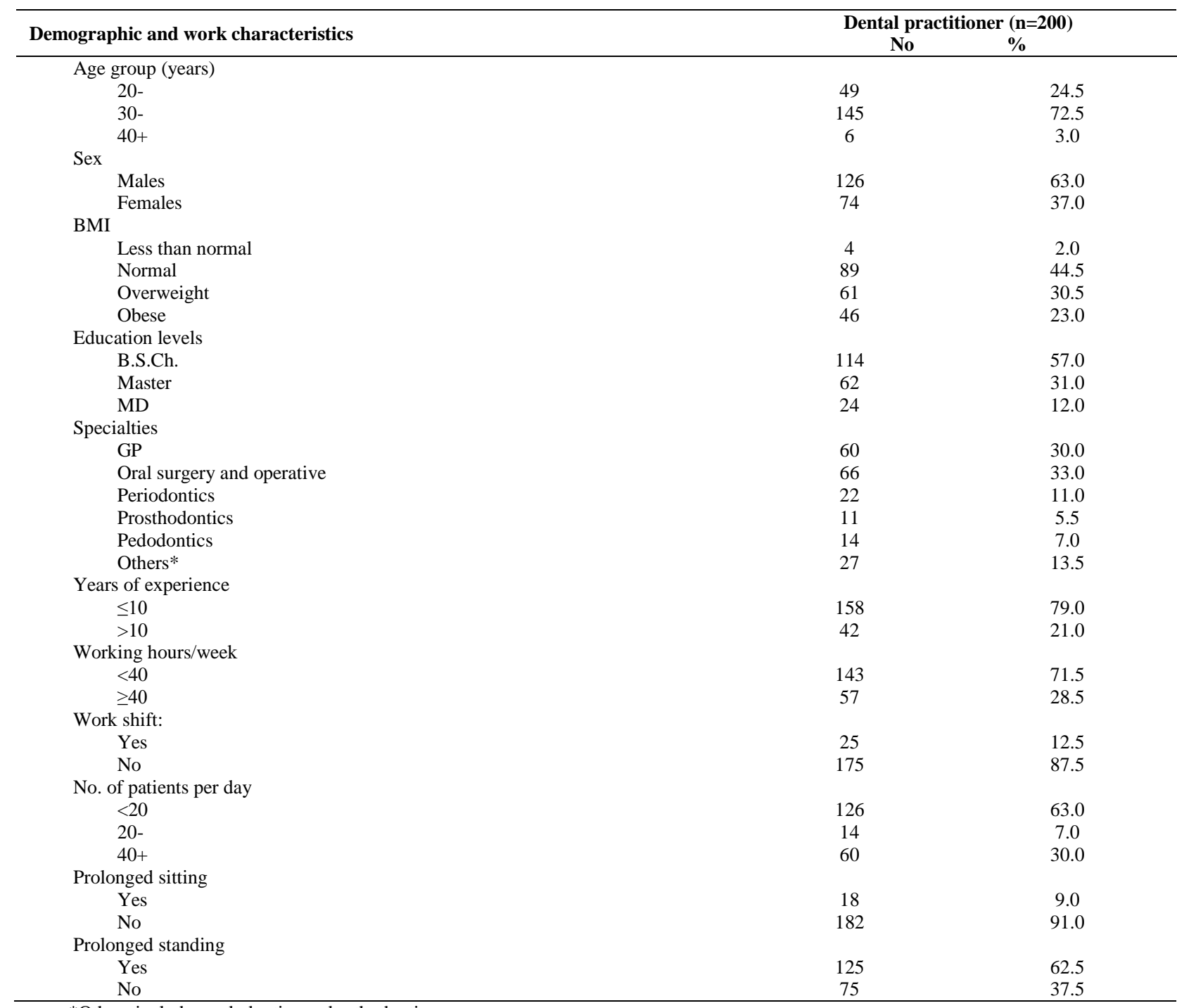

*Others includes endodontics and orthodontics.

Table 2: Musculoskeletal disorders among dental practitioners in the last 12 months and their relation to demographic and work characteristics

\begin{tabular}{|c|c|c|c|c|c|}
\hline \multirow{3}{*}{ Demographic and work characteristics } & \multicolumn{4}{|c|}{ (MSD) among Dental practitioners } & \multirow{3}{*}{$P^{*}$} \\
\hline & \multicolumn{2}{|c|}{$\begin{array}{l}\text { present } \\
(n=144)\end{array}$} & \multicolumn{2}{|c|}{$\begin{array}{c}\text { Absent } \\
(\mathbf{n}=56)\end{array}$} & \\
\hline & No & $\%$ & No & $\%$ & \\
\hline \multicolumn{6}{|l|}{ Age group (years): } \\
\hline $20-$ & 35 & 24.3 & 14 & 25.0 & 0.332 \\
\hline $30-$ & 105 & 72.9 & 40 & 71.4 & \\
\hline $40+$ & 4 & 2.8 & 2 & 3.6 & \\
\hline \multicolumn{6}{|l|}{ Sex } \\
\hline Males & 95 & 66.0 & 31 & 55.4 & 0.163 \\
\hline Females & 49 & 34.0 & 25 & 44.6 & \\
\hline \multicolumn{6}{|l|}{ BMI } \\
\hline Less than normal & 4 & 2.8 & 0 & 0.0 & 0.121 \\
\hline Normal & 70 & 48.6 & 19 & 33.9 & \\
\hline Overweight & 40 & 27.8 & 21 & 37.5 & \\
\hline obese & 30 & 20.8 & 16 & 28.6 & \\
\hline
\end{tabular}




\begin{tabular}{|c|c|c|c|c|c|}
\hline \multicolumn{6}{|l|}{ Education levels: } \\
\hline B.S.Ch. & 83 & 57.6 & 31 & 55.4 & \multirow[t]{3}{*}{0.958} \\
\hline Master & 44 & 30.6 & 18 & 32.1 & \\
\hline MD & 17 & 11.8 & 7 & 12.5 & \\
\hline \multicolumn{6}{|l|}{ Specialties: } \\
\hline GP & 43 & 29.9 & 17 & 30.4 & \multirow{6}{*}{0.571} \\
\hline Oral surgery and operative & 48 & 33.4 & 18 & 32.1 & \\
\hline Periodontics & 13 & 9.0 & 9 & 16.1 & \\
\hline Prosthodontics & 10 & 6.9 & 1 & 1.8 & \\
\hline Pedodontics & 10 & 6.9 & 4 & 7.1 & \\
\hline Others** & 20 & 13.9 & 7 & 10.8 & \\
\hline \multicolumn{6}{|l|}{ Years of experience } \\
\hline$\leq 10$ & 121 & 84.0 & 37 & 66.0 & \multirow[t]{2}{*}{0.005} \\
\hline$>10$ & 23 & 16.0 & 19 & 34.0 & \\
\hline \multicolumn{6}{|l|}{ Working hours/week: } \\
\hline$<40$ & 108 & 75.0 & 35 & 62.5 & \multirow[t]{2}{*}{0.084} \\
\hline$\geq 40$ & 36 & 25.0 & 21 & 37.5 & \\
\hline \multicolumn{6}{|l|}{ Work shift: } \\
\hline Yes & 20 & 86.1 & 51 & 91.1 & \multirow[t]{2}{*}{0.341} \\
\hline No & 124 & 13.9 & 5 & 8.9 & \\
\hline \multicolumn{6}{|l|}{ Patients per day: } \\
\hline$<20$ & 90 & 62.5 & 36 & 64.3 & \multirow[t]{3}{*}{0.851} \\
\hline $20-$ & 11 & 7.6 & 3 & 5.4 & \\
\hline $40+$ & 43 & 29.9 & 17 & 30.4 & \\
\hline \multicolumn{6}{|l|}{ Prolonged sitting: } \\
\hline Yes & 17 & 11.8 & 1 & 1.8 & \multirow[t]{2}{*}{0.026} \\
\hline No & 127 & 88.2 & 55 & 98.2 & \\
\hline Prolonged standing: & & & & & 0.745 \\
\hline Yes & 91 & 63.2 & 34 & 60.7 & \\
\hline No & 53 & 36.8 & 22 & 39.3 & \\
\hline
\end{tabular}

** Orthodontics, Endodontics and Operative alveolar surgery.

Table 3: Binary logistic regression analysis for most for the most relevant risk factors for MSD in dental practitioners

\begin{tabular}{lcc}
\hline Studied risk factors & OR* $(\mathbf{9 5 \%} \mathbf{C I}) * *$ & $\boldsymbol{P}$ \\
\hline Years of experience & $0.320(0.152-0.671)$ & 0.033 \\
Non- prolonged sitting & $9.522(1.197-75.773)$ & 0.003 \\
\hline$\quad *$ OR=Odds ratio & & \\
$\quad * * \mathrm{CI}=$ confidence interval \\
$\quad$ Variables included in logistic regression were years of experience and non-prolonged sitting.
\end{tabular}

Duration of current work and non-prolonged sitting during work were still significantly associated with MSD after adjustment for age and sex $(\mathrm{OR}=0.320$; 95\% CI: $0.152-0.671$ and $\mathrm{OR}=9.522 ; 95 \%$ CI: $1.197-$ 75.773; respectively) as shown in table (3). The most common areas affected with MSD in order of magnitude were low back (52.0\%), upper back pain (44.0\%), ankles and feet (30.0\%), knees (29.5\%) and hips/thighs (27.5\%). Prevalence of MSDs was similar for male and female practitioners irrespective of the area involved, (Table 4).

There was no significant relationship between specialties of dental practitioners and the prevalence of MSD at all regions except for neck disorders which was statistically significant $(\mathrm{P}=0.053)$ among periodontics (40.9\%) followed by prosthodontics (36.4\%). About $23.0 \%$ of the practitioners were complaining of MSD in two areas of their bodies in the last twelve months, while $(22.0 \%)$ of them were complained in five areas (Table 5). Otherwise, $(14.0 \%)$ of the participants were complaining in three areas as shown in figure (1).

More than half of the dental practitioners with MSD $(54.0 \%)$ required sick leave (1-7 days) from their practice during the preceding twelve months. MSD was seen to be an ongoing problem on assessment of the seven day sick leaves, hospitalizations (4.8\%), alteration of duties (6.9) as well as reduction in work activity (47.9\%), leisure activity (42.4\%) and doctor consultations (30.0\%) of dental practitioners with MSD as shown in table (6). 
Table 4: Prevalence of musculoskeletal disorders in the last 12 months at different regions in dental practitioners in relation to sex

\begin{tabular}{|c|c|c|c|c|}
\hline Site & $\begin{array}{c}\text { Males }(n=126) \\
\text { no }(\%)\end{array}$ & $\begin{array}{c}\text { Females }(n=74) \\
\text { no }(\%)\end{array}$ & $\begin{array}{c}\text { Total }(n=200) \\
\text { no }(\%)\end{array}$ & $\mathbf{P}$ \\
\hline Neck & $28(22.2)$ & 11(14.9) & $39(19.5)$ & 0.205 \\
\hline Shoulders & $27(21.4)$ & $10(13.5)$ & $37(18.5)$ & 0.164 \\
\hline Elbows & 14(11.1) & $7(9.5)$ & $21(10.5)$ & 0.713 \\
\hline Wrists/hands & $23(18.3)$ & $8(10.8)$ & $31(15.5)$ & 0.160 \\
\hline Upper back & $58(46.0)$ & $30(40.5)$ & $88(44.0)$ & 0.450 \\
\hline Lower back & $66(52.4)$ & $38(51.4)$ & $104(52.0)$ & 0.888 \\
\hline Hips/thighs & $36(28.6)$ & $19(25.7)$ & $55(27.5)$ & 0.658 \\
\hline Knees & $40(31.7)$ & $19(25.7)$ & $59(29.5)$ & 0.363 \\
\hline Ankles/feet & $38(30.2)$ & $22(29.7)$ & $60(30.0)$ & 0.205 \\
\hline
\end{tabular}

Table 5: Prevalence of musculoskeletal disorders in the last 12 months in different dental specialties

\begin{tabular}{|c|c|c|c|c|c|c|}
\hline Site & $\begin{array}{c}\text { Gp }(n=60) \\
\text { no }(\%)\end{array}$ & $\begin{array}{c}\text { Oral surgery and } \\
\text { operatives }(n=66) \\
\text { no }(\%)\end{array}$ & $\begin{array}{c}\begin{array}{c}\text { Periodontics } \\
(\mathbf{n}=22) \\
\text { no }(\%)\end{array} \\
\end{array}$ & $\begin{array}{c}\begin{array}{c}\text { Prosthodontics } \\
(n=11) \\
\text { no }(\%)\end{array} \\
\end{array}$ & $\begin{array}{c}\begin{array}{c}\text { Pedodontics } \\
(n=14) \\
\text { no }(\%)\end{array} \\
\end{array}$ & $\begin{array}{r}\text { Others } \\
(\mathrm{n}=27) \\
\text { no }(\%)\end{array}$ \\
\hline Neck & $9(15.0)$ & $11(16.7)$ & $9(40.9)$ & $4(36.4)$ & $1(1.7)$ & $5(18.5)$ \\
\hline Shoulders & $8(13.3)$ & $10(15.2)$ & $7(31.8)$ & $4(36.4)$ & $2(14.3)$ & $6(22.2)$ \\
\hline Elbows & $5(8.3)$ & $6(9.1)$ & $2(9.1)$ & $1(9.1)$ & $2(14.3)$ & $5(18.5)$ \\
\hline Wrists/hands & $6(10.0)$ & $11(16.7)$ & $5(22.7)$ & $3(27.3)$ & $1(7.1)$ & $5(18.5)$ \\
\hline Upper back & $26(43.3)$ & $29(43.9)$ & $7(31.8)$ & $8(72.7)$ & $8(57.1)$ & $5(26.3)$ \\
\hline Lower back & $32(53.3)$ & $37(56.1)$ & $7(31.8)$ & $7(50.0)$ & $7(50.0)$ & $10(37.0)$ \\
\hline Hips/thighs & $21(35.0)$ & $19(28.8)$ & $6(27.3)$ & $4(36.4)$ & $2(14.3)$ & $14(51.9)$ \\
\hline Knees & $22(36.7)$ & $17(25.8)$ & $8(36.4)$ & $3(27.3)$ & $4(28.6)$ & $5(18.5)$ \\
\hline Ankles/feet & $22(36.7)$ & $21(31.8)$ & $6(27.3)$ & $3(27.3)$ & $3(21.0)$ & $5(18.5)$ \\
\hline
\end{tabular}

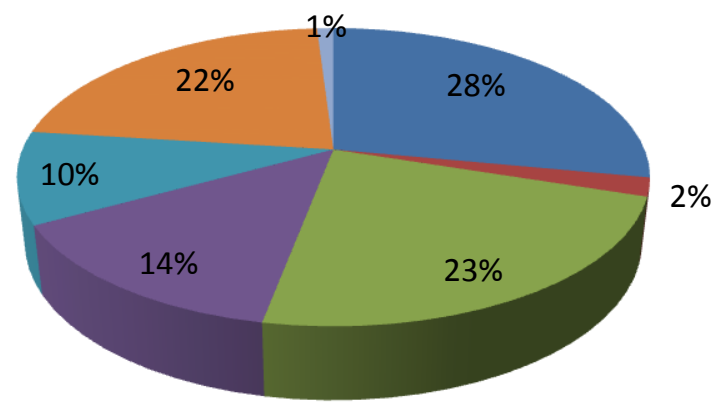

No symptoms

- One area

Two areas

Three areas

Four areas

Five areas

Figure 1: Distribution of the dental practitioners in relation to the number of areas involved by MSD in the last 12 months.

Table 6: Effect of MSD in the last 12 months on the daily activities of in dental practitioners.

\begin{tabular}{|c|c|c|}
\hline \multirow{2}{*}{ Effect of MSD } & \multicolumn{2}{|c|}{ Dental practitioner $(n=144)$} \\
\hline & No & $\%$ \\
\hline Reduction in work activity & 69 & 47.9 \\
\hline Reduction in leisure activity & 61 & 42.4 \\
\hline Alteration of duties & 10 & 6.9 \\
\hline Doctor consultations & 44 & 30 \\
\hline Hospitalizations & 7 & 4.8 \\
\hline \multicolumn{3}{|l|}{ Sick leaves (days) } \\
\hline $1-7$ & 78 & 54.0 \\
\hline $8-30$ & 12 & 8.3 \\
\hline$>30$ & 3 & 2.1 \\
\hline
\end{tabular}




\section{DISCUSSION}

Musculoskeletal disorders among dentists are one of the most important work-related problems reported worldwide. ${ }^{(12)}$ This study examined the prevalence and distribution of self-reported MSD among dentists in Alexandria, Egypt. The dentists were asked to note the occurrence of pain and discomfort over the past 12 months. The present study showed high prevalence of MSD among dentists $(72.0 \%)$ that could be attributed to prolonged static postures, repetitive movements, use of force and vibrations, which are considered to be risk factors for MSD. ${ }^{(13)}$ This prevalence coincides with a study conducted in Iran ${ }^{(14)}$ and New Zealand ${ }^{(15)}$ where $73.0 \%$ and $71.0 \%$ of dentists respectively reported MSDs. On the other hand, this prevalence was higher than that reported by practitioners in Saudi Arabia $(59.2 \%)^{(16)}$ but was lower than reports from Australia $(87.2 \%),{ }^{(17)}$ Lithuania $(86.5 \%),{ }^{(5)}$ and Turkey $(94 \%) .{ }^{(18)}$ Unexpectedly, the non-significant difference between males and females regarding the prevalence MSDs may be attributed to the predominance of the male gender in the present study. Similarly, a study done in Pakistan revealed that the prevalence of symptoms of MSDs between male and female dentists wasn't statistically significant. ${ }^{(19)}$ On the contrary of this result ,studies assessing the prevalence of MSD among dental practitioners in Lithuania, ${ }^{(20)}$ and New Zealand ${ }^{(15)}$ have shown higher prevalence of MSD among female practitioners. They explained these results by the fact that women were more concerned about their health compared to men and tended to report health problems more often. In addition, Female dentists reported neck symptoms 1.4 times more often than male dentists did. ${ }^{(21)}$ In addition, an Iranian study ${ }^{(14)}$ found that the prevalence of symptoms of MSDs only in the wrist/ hand area was significantly more in women than in men. In the present study, no correlation was found between the frequency of MSD symptoms and the age of dental practitioners. This finding is similar to the results of recent studies conducted in Saudi Arabia. ${ }^{(16)}$ On the other hand, studies among dental practitioners in Poland and Lithuania ${ }^{(5),}{ }^{(22)}$ have shown that MSDs increased with age. This study revealed that years of experience is a significant risk factor for MSD as the highest prevalence was reported when the dentist had $\leq 10$ years of experience. This could be due to the fact that experienced dentists are probably better at adjusting their working position and techniques in order to avoid musculoskeletal problems compared to their less experienced counterparts, or they simply developed coping strategies to deal with the pain ${ }^{(1)}$. Another more likely explanation, however, is simply that those dentists with severe MSDs would have ceased working, and would thus not have been included in this study. This is called the healthy-worker effect. ${ }^{(23)}$ Neither the numbers of patients examined per day by dental practitioners nor their working hours per week affected the prevalence of MSDs in our study as the majority of the participants worked less than 40 hours/ week $(71.5 \%)$ and examined less than 20 patients/day (63.0\%). This result coincides with a study conducted in Iraq ${ }^{(24)}$ which revealed that no significant difference was observed between weekly working hours and prevalence of back and neck problems. No significant association was found between the BMI and the prevalence of MSDs in the present study as about half of the participants (46.5\%) had normal weight underweight. On the other hand, a study done in New Zeland ${ }^{(25)}$ reported that there were no significant differences between BMI and prevalence of MSDs, except for hip/thigh symptoms. In the current study prolonged sitting was not considered a risk factor for MSDs as the majority of the practitioners complaining of MSDs (88.2\%) did not report prolonged sitting but, while about all of the practitioners who reported prolonged sitting during their work (17 out of 18) complained of MSDs. Such finding may be due adopting awkward postures that may be the greatest risk factor for such disorders. Other researchers have confirmed the presence of awkward postures specifically in the neck, back, shoulders, hand and wrist for dental professionals. Awkward postures are often taken due to improper seating, improper patient positioning and/or poor work techniques. Common awkward postures in dental practice include elbow and wrist flexion and thumb hyperextension, which have been shown to stress the neurovascular structures and ligaments. ${ }^{(26)}$ On the contrary, Pope et al, ${ }^{(27)}$ stated that the inactivity associated with sitting might cause fatigue as well as injury. Inactivity can cause a buildup of metabolites that can contribute to disc degeneration and disc herniation in both the cervical and lumbar spines. Additionally, in sitting, the lack of motion statically loads muscles, ligaments, and joint tissues (passive tissue forces), which can accelerate disc degeneration and increase the risk of herniation. The findings of this study showed no significant association between prolonged standing and the development of MSDs. This result was different from the result of the study done by Kierklo et al, ${ }^{(28)}$ who stated that the standing position while treating a patient was significantly more often related to pain in the knees and feet, as reported by $25 \%$ of the surveyed dentists working in a standing position. The commonest site for MSD complains in this study was low back pain (52.0\%) followed by upper back pain $(44.0 \%)$.It has been proven that postures which may exert a higher pressure on intervertebral disk as well as prolonged spinal hypo mobility are among important factors leading to degenerative changes in the lumbar spine and subsequent low back pain. Since such postures are not uncommon in daily practice of a 
dentist, some authors believe that they are at a higher risk of developing low back pain than other job groups. ${ }^{22}$ This was lower than the prevalence in Taiwan $(66.5 \%)^{(29)}$, Denmark $(60 \%)$, Poland (60\%)and Australia $(54 \%)^{(2)}$, but equal to the prevalence in Saudi Arabia (52\%), ${ }^{(16)}$, and higher than the prevalence in Netherlands $(45 \%){ }^{(2)}$ The third commonest site of MSDs in our study was the ankles and feet $(30.0 \%)$ This could explained by prolonged standing especially in oral surgery and operative specialists who constituted $33.0 \%$ of the participants. These results coincided with a Nigerian study ${ }^{(30)}$ where the prevalence of ankle/feet complains among dentists was $55.7 \%$. Dentists are predisposed to pain or injury in different sites of the body depending on the type of work and the position adopted. $^{(10)}$ This study showed no significant differences in the prevalence of MSD in relation to specialties of dental practitioners except for neck pain that was highest in periodontics and prosthodontics (40.9\% and 36.4\%; respectively).Long work duration and repetitive movements of periodontal treatments could be the main reasons that predisposed them to higher risk of MSDs. ${ }^{(31)}$ Also, scaling procedures involving both waving and rotary motion power strokes have been classified as the most demanding task required by hygienists. ${ }^{(32)}$

MSDs affect the physical, psychological, and social aspects of practitioners. ${ }^{(33),}{ }^{(17)}$ This in turn has impacts on their productivity and ultimately reduces the quality of life of the practitioners. In the present study, among dental practitioners complaining of MSD over a period of 12 months, there was reduction in work activity (47.9\%), leisure activity $(42.4 \%)$, percentage taking sick leaves, consultations with doctor (30.0\%) and hospitalization. Majority of the practitioners with MSD (54.0\%) took1-7 days of sick leaves from practice irrespective of the site of MSD, which was in accordance with other studies. ${ }^{(15),(34)}$ A survey of dental hygienists in the United States found that those with pre-existing pain were absent from practice due to MSD for an average of five weeks per year, while more than $40 \%$ of dentists in the United States reduced their work hours due to MSD ${ }^{(35)}$ and Swedish dentists with a high prevalence of MSD were more likely to leave their profession. ${ }^{(23)}$

One of the major limitations of this type of study is that the results were based on the self-reported experiences of the respondents. Using physical examinations in this study would provide more detailed information. This study also had the potential for recall bias because it asked the participants to remember musculoskeletal complaints and information regarding the past year. The participants who experienced pain may be more likely to remember events and volunteer that information, which leads to response bias. Stress and dissatisfaction with employment was not addressed in this survey; however, it can influence the amount of discomfort persons experience in their job.

\section{CONCLUSION AND RECOMMENDATIONS}

The prevalence of MSD symptoms is high among the dental practitioners in Alexandria, Egypt which affects the daily practice of nearly half of them. Lower and upper back symptoms were particularly common. Further studies are needed to identify the factors, which will reduce the prevalence of the musculoskeletal symptoms among dental practitioners. Therefore, it is recommended that an appropriate training program be implemented to improve dentists' awareness about musculoskeletal symptoms and ways of their prevention.

\section{CONFLICT OF INTEREST}

All authors declare no conflict of interest.

\section{REFERENCES}

1. Leggat PA, Kedjarune U, Smith DR. Occupational health problems in modern dentistry: a review. Ind Health. 2007;45:611-21.

2. Hayes MJ, Cockrell D, Smith DR. A systematic review of musculoskeletal disorders among dental professionals. Int $\mathbf{J}$ Dent Hyg. 2009;7:159-65.

3. Morse T, Bruneau H, Dussets chleger J. Musculoskeletal disorders of the neck and shoulder in the dental professions. Work. 2010;35:419-29.

4. Hayes MJ, Smith DR, Cockrell DJ: An international review of musculoskeletal disorders in the dental hygiene profession. Int Dent J 2010, 60(5):343-352.

5. Puriene A, Janulyte V, Musteikyte M, et al, .General health of dentists. Literature review. Stomatologija. 2007; 9(1):10-20.

6. Hayes MJ, Smith DR, Taylor JA. Musculoskeletal and symptom severity among Australian dental hygienists BMC Research Notes. 2013;6:250. available at// http://www.biomedcentral.com/1756-0500/6/250disorders.

7. Jabbari H. Musculoskeletal Symptoms in Workers. International Journal of Occupational Safety and Ergonomics (JOSE) 2008, 14:(4): 455-62.

8. Johanning E, Bruder R. Low Back Disorders and Dentistry: stress factors and ergonomic intervention. IN: Murphy, D.C. (Editor), (1998).Ergonomics and the Dental Care Worker. Washington, DC: American Public Health Association.

9. Sanders MJ, Turcotte, CA. Ergonomic strategies for dental professionals work.1997; 8: 55-72

10. University of British Columbia (UBC). Dental Clinical Ergonomics: study module.(2008).Available Online:www.dentistry.ubc.calergo/

11. Leggat PA, Smith DR, Clark MJ. Prevalence and correlates of low back pain among occupational therapy students in Northern Queensland. Can J Occ.2008; 75(1):35-41.

12. Diniz de Carlvalho MV, Soriano EP, Caldas Jr. Work-related musculoskeletal disorders among Brazilian dental students. Journal of Dental Education.2009; 73(5): 624-30.

13. Valachi B and Valachi K. Preventing musculoskeletal disorders in clinical dentistry: strategies to address the mechanisms leading to musculoskeletal disorders. Journal of the American Dental Association.2003; 134(12): 1604-12. 
14. Rabiei M, Shakiba M, Shahreza H, Talebzadeh M. Musculoskeletal Disorders in Dentists. Iranian Occupational Health Association (IOHA). 2012; 4: 36-40

15. Ayers K, Thomson W, Newton J, Morgaine K, Rich A. Selfreported occupational health of general dental practitioners. Occupational Medicine. 2009; 59:142-8

16. Abdul-Jabbar TA. Musculoskeletal disorders among dentists in Saudi Arabia. Pak Oral and Dental Journal.2012; 28(1): 135-44.

17. Leggat PA, Smith DR. Musculoskeletal disorder self-reported by dentists in Queensland, Australia. Australia Dental Journal. 2006; 51(4): 324-7.

18. PolatZ, BaskanS, Altun S, Tacir. Musculoskeletal symptoms of dentists from South-East Turkey. Biotechnology and Biotechnological Equipment.2007; 21(1): 86-90.

19. RehmanK, AyazH, Urooj W, Raiq Shah. Work-related musculoskeletal disorders among dental practitioners in Khyber Pakhtunkhwa. Pakistan Oral \& Dental Journal. 2013; 33 (3):531-4.

20. Puriene A, BalciunieneI, Janulyte V.Specificity of chronic selfreported occupational hazards among male and female Lithuanian dentists. ActaMedicaLituanica.2008;15: 55-60.

21. Mangharam J, McGlothan, JD.Ergonomics, and Dentistry: A literature review.IN: Murphy, D.C. (Editor), (1998). Ergonomics and the Dental care Worker. Washington, DC: American Public Health Association.

22. PurieneA, J, Aleksejuniene J, Petrauskiene I, Balciuniene I, Janulyte V. Self-reported occupational health issues among Lithuanian dentists. Industrial Health. 2008; 46 (4): 369-74.

23. AkessonI, Johnsson B, Rylander L. Musculoskeletal disorders among female dental personnel -clinical examination and a 5year follow-up study of symptoms. Int Arch Occup. Environ Health. 1999; 72:395-403.

24. Zaheda J. Musculoskeletal disorders: back and neck problems among a sample of Iraqi dentists in Baghdad city. J Bagh College Dentistry.2011; 23(4): 90-5.
25. Sam A, MoffaS, Thomson W. Musculoskeletal symptoms in New Zealand dental therapists: prevalence and associated disability. New Zealand Dental Journal. 2008; 104 (2): 49-53.

26. Occupational Health and safety council of Ontario (OHSCO). MSD Preventionseries 2007; part 1"MSD PreventionGuideline for Ontario"available online athttp//:www .iwh.on. camsd prevention ont guideline 2007\%20(4).pdf

27. Pope MH, Goh KL, Magnusson ML. Spine ergonomics. Annu Rev Biomed Eng. 2002;4:49-68.

28. Kierklo A, Kobus A, Jaworska M, BotulińskiB. Work-related musculoskeletal disorders among dentists - a questionnaire survey.Ann Agric Environ Med.2011, 18, 79-84.

29. Tzu-Hsien L, Yen Chun L, Tien-Yu H, Hsiao F, Lai Y, Chang C.Prevalence of and risk factors for musculoskeletal complaints among Taiwanese dentists. Journal of Dental Sciences. 2012; 7 : 65-71

30. UdoyeC, AguwaE.Musculoskeletal Symptoms: A Survey Amongst A Selected Nigerian Dentists. The Internet Journal of Dental Science. 2006; 5 (1) operations@ispub.com.

31. JianruYI, Xiangxiang HU, Boxi YAN, Wei ZHENG, Yu LI, Zhihe ZHAO. High and specialty-related musculoskeletal early training years. J Appl Oral Sci. 2013;21(4):376-82.

32. Horstman SW, Horstman BC, Hostman FS. Ergonomic Risk Factors Associated with thepractice of Dental Hygiene: a preliminary study. Journal of professional safety, 1997; 42(4):49-53.

33. Alexopoulos E, StathiI, Charizani F. Prevalence of musculoskeletal disorders in dentists. BMC Musculoskeletal Disorders.2004; 5: 16.

34. RudPargali N, Jowkar N. Prevalence of musculoskeletal pain among dentists in Shiraz, Southern Iran," International Archives of Occupational and Environmental Health.2010; 1 (2): 60-74.

35. Osborn J, Newell K, Rudney JD, Stoltenberg JL. Musculoskeletal pain among Minnesota dental hygienists. J Dent Hyg.1990; 64(3):132-8. 
El Dalatony et al. 